\title{
An overview on test generation from functional requirements
}

\author{
M.J. E s c a lo n a, J.J. G u t i e r r e z, M. M e jía s, G . \\ A r a gón, I. R a mos, J. T o r r e s, F. J. D o m í n g e z
}

\begin{abstract}
A B S T R A C T
Despite the fact that the test phase is described in the literature as one of the most relevant for quality assurance in software projects, this test phase is not usually developed, among others, with enough resources, time or suitable techniques.

To offer solutions which supply the test phase, with appropriate tools for the automation of tests

Keywords:

Testing

Early testing

Functional test generation generation, or even, for their self-execution, could become a suitable way to improve this phase and reduce the cost constraints in real projects.

This paper focuses on answering a concrete research question: is it possible to generate test cases from functional requirements described in an informal way? For this aim, it presents an overview of a set of relevant approaches that works in this field and offers a set of comparative analysis to determine which the state of the art is.
\end{abstract}

\section{Introduction}

Nowadays, there is an important research community focus-ing on the necessity of an efficient test phase in software project and there are interesting discussions and research works deal-ing with the way of getting this efficiency. The test phase is one of the most relevant to both assure the quality of a system and measure the correspondence of the system with the users' expectations.

The objective of software testing is the evaluation of a system or component through its execution, starting from given initial conditions and observing the results (IEEE, 2008). The establishment of such initial conditions consumes much of the effort spent in the development of test cases and testing techniques.

However, despite software community supports the importance of the test phase, it is not always scheduled, executed or faced up with enough resources in real projects. This fact has to do with some aspects such as delays in the development process that commonly generate resources scraps or lack of initial structure of the test in project planning.

In the wide range of tests that can be analyzed, this paper focuses on functional test cases. One of the most important aspects to consider in tests is both the degree of coverage of the initial require-ments defined at the beginning of the project and its validation with final users. Thus, the term early testing (Gutiérrez et al., 2006) is used to define a line in test research oriented to enhance the systematic implementation of test cases based on system requirements or business models.

Information systems are designed to fulfill a set of requirements. These requirements describe, among other aspects, the functionality of the system. The set of requirements that describes the functional necessities of the system is named in this paper Functional Requirements. Probably, these functional requirements are based on system objectives or are in need of future users of the system.

For these reasons, a critical task is to assure the right implementation of the expected functionality in the final software. One of the main tools to achieve this goal is system testing, which is a mechanism to verify that the system performs the behavior expressed in its requirements. Thus, test cases must exercise the system under the scope of the requirements. This task makes the requirements, not only a right tool to validate the execution of test cases, but also a source of test cases. Functional Test Cases is the name given in this paper to the set of system tests cases that enables the validation of functional requirements, independently how they are obtained. When mentioning test cases 2 from functional requirements, we are referring to the set of functional test cases that is obtained in a systematic way from the functional requirement definition.

Therefore, some interesting questions to investigate are whether it would be possible to obtain the total functional test cases from functional requirements and how easy and automatic this process would be.

This systematic generation can be a suitable way to facilitate the execution of the test phase for it offers systematical processes that enable the test generation and test definition in a formal, economic and efficient way. Besides, it guarantees the traceability of the final system with the initial requirements. Thus, this paper 
Table 1

Detailed name of the studied approaches.

\begin{tabular}{|c|c|c|}
\hline Year & Title & Reference \\
\hline 1988 & Category-Partition Method & Ostrand and Balcer (1988) \\
\hline 1997 & Software Requirements and Acceptance Testing & Hsia $(1994,1997)$ \\
\hline 1999 & Testing Object-Oriented Systems & Binder (1999) \\
\hline 1999 & Test Cases Generation from UML State Diagrams & Kim et al. (1999) \\
\hline 2000 & Automated Test Case Generation from Dynamic Models & Fröhlich and Link $(1999,2000)$ \\
\hline 2000 & Writing Effective Use Cases & Cockburn (2000) \\
\hline 2002 & Testing From Use Cases Using Path Analysis Technique & Naresh (2002) \\
\hline 2002 & Generating Test Cases from Use Cases & Heumann (2002) \\
\hline 2002 & A UML-Based Approach to System Testing (TOTEM) & Labiche and Briand (2002) \\
\hline 2002 & Use Cased Derived Test Cases & Wood and Reis (2002) \\
\hline 2002 & Quality Web Systems & Dustin (2002) \\
\hline 2003 & Scent: A Method Employing Scenarios to Systematically Derive Test Cases for System Test & Ryser and Glinz (2003) \\
\hline 2003 & What Is Requirements-Based Testing? & Mogyorodi $(2001,2002,2003)$ \\
\hline 2003 & Statistical Usage Testing Based on UML & Huebner et al. (2003), Riebisch et al. (2002) \\
\hline 2003 & Traceability from Use Cases to Test Cases & Zielczynski (2006) \\
\hline 2004 & RETNA: From Requirements to Testing in Natural Way & Boddu et al. (2004) \\
\hline 2004 & PLUTO: A Test Methodology for Product Families & Bertolino and Gnesi (2004) \\
\hline 2004 & A UML-based Test Generation and Execution & Ruder (2004) \\
\hline 2006 & Automatic Test Generation: A Use Case Driven Approach & Nebut and Fleurey (2003), Nebut et al. (2006) \\
\hline 2007 & An Automatic Tool for Generating Test Cases from the System's Requirements & Ibrahim et al. (2007), Ismail et al. (2007) \\
\hline 2008 & REED. Requirement Editor & Oh et al. (2008) \\
\hline 2007 & Test Cases Generation from Use Cases & Gutiérrez et al. (2008a,b) \\
\hline 2009 & Software Product Line Testing & Pérez et al. (2009) \\
\hline 2009 & Bridging Test and Model-driven Approaches in Web Engineering & Robles et al. (2009) \\
\hline
\end{tabular}

presents an overview to quantify the degree of maturity, systematization and automation of the existing works about the generation of functional test cases from functional requirements described in natural languages or, at least, in an informal language. In the literature, there are several approaches like (Liu and Yuting, 2008; Stocks and Carrington, 1996) or (TerMaat, 2001) that offer suitable results in the systematic generation of test cases. Still, they start with a formal definition of the requirements by using formal specification. The use of formal languages to define requirements probably provides the best solutions for both, test generation and requirements validation in general, as it is concluded in Ryser and Glinz (1999). Nevertheless, they are difficult to apply in the enterprise environment (Insfrán et al., 2002). For these reason, the study only considers approaches based on functional requirements described in natural or informal language.

Survey generation has been driven by using the guide proposed in SEG (2007). This process consists in three main activities:

1. Planning. In this phase, the survey is planned and delimited and a specific protocol to set it up must be defined. Both, the aims of the survey and the environment and sources to identify the approach of study, must be clearly and completely defined.

2. Conducting the review. In this phase, after the initial constraints have already been specified, the subject of study must be identified and reviewed with different sources. Then, the set of relevant approaches to be analyzed is detected. SEG (2007) proposes to establish a common characterization criterion to define each approach before the comparative study is carried out. It enables to obtain a uniform definition of each approach that may facilitate the comparative study.

3. Reporting the review. Finally, once the approaches have been studied and the research situation has already been analyzed, the process concludes with a report on the results of the review. In fact, this paper represents the result of our review. Previous phases were executed before writing this paper, as referenced in it.

In order to present the overview results, this paper is organized as follows: Section 2 introduces other related surveys about the test cases generation from functional requirements and Section 3 describes the method used to select approaches in the study, and it also introduces a characterization schema to normalize the information of each of the approaches found. This section involves the first and second phases of SEG.

In Section 4, by means of the characterization schema, the paper sets out the characterization schema of the approaches analyzed in this survey as well as other related approaches. From this global and homogeneous view of every approach of study, Section 5 analyzes the information obtained from the set of approaches and presents some relevant studies. Finally, Section 6 states the conclusions and ongoing work.

\section{Related work}

This paper is not the first one dealing with this subject. There are, at least, three previous comparative studies written with the same aim than this one. In this section, three previous surveys are related and related to this comparative study.

A. The first study presented by Ryser and Glinz (1999) introduce a division and characterization of approaches for validating and testing requirements. In the scope of approaches for testing functional requirements, this reference proposes a division among approaches which work with informal requirements (defined, for example, as text templates), approaches working with semiformal requirements (defined, for example, as state-machines) and those which deals with formal requirements (defined, for example, with algebraic languages). Nevertheless, this paper puts forward that functional requirements defined in natural language and with text templates are not valid for a process of generating test cases.

B. The second study, developed by Denger and Medina (2003), explains and analyzes 12 approaches for generating test cases from functional requirements. In this comparative study, they conclude that most of the analyzed approaches work with functional requirements in natural language and the study, in turn, reveals the low uniformity and lack of standards in this area.

C. The third survey was conducted by Gutiérrez et al. (2006) in a previous research work. 8 out of 12 approaches are analyzed in a different line from Denger and Medinaǐs. Again, the main conclusion is the lack of a common line and a global solution for functional test cases generation. 
Starting with these studies and with future work oriented towards finding a suitable solution for test generation, the follow up of this paper is an in-depth analysis of the present situation, focusing on approaches that describe requirements in an informal way, and tries to formalize the comparative study by means of characterization schemas (in the next section). It also enlarges on new approaches not studied in any of the previous surveys and compares the results of these previous surveys.

\section{Planning and conducting the review}

One of the most important tasks in carrying out a survey is to clearly delimit the scope of the approaches that are relevant for the study. However, one problem is how to present each approach in a homogeneous way to be compared. As introduced, according to SEG (2007), the characteristics that approaches should fulfill must be consistent with the thesis of this survey: generation of test cases from functional requirements described in informal language. Thus, following the terminology described in Brereton et al. (2007) for a concrete planning and development of our review, we define:

Context: The systematic, or even automatic generation of test cases from functional requirements, could be a solution to improve the test phase and reduce its cost. There are several approaches that offer different solutions in this area, so a critical overview will be introduced in order to quantify the degree of maturity, systematization and automation of the existing works about generation of functional test cases from functional requirements. This study will focus on approaches that deal with requirements described in informal languages since a previous comparative study, introduced in Section 2, concludes that the formal description of functional requirements makes easier test cases generation. Nevertheless, this notation is not commonly used in the enterprise environment. We want to analyze approaches that define functional requirements in informal languages, like scenarios, patterns, etc., but are widely used in real projects.

Thus, approaches presented in our study must conform to our research line of argumentation

1. The generation process must start from the functional specification of the tested system.

2. The functional specification must be written in non-formal languages.

3. The result must be system test cases.

The relevant approaches for this survey are those that start from the functional specification of the system, should be expressed in the form of functional requirement, use case or usage scenarios and are written in a natural language or similar. There are no constraints on either the structure or size of the approaches. In the survey, the only approaches that are included are the ones which describe how to obtain functional system test cases. This means that generated test cases allow verifying the right implementation of the functional specification in the tested system. Following these criteria, if an approach does not follow these constraints will not be included in the survey. In Section 4.14, an overview of some excluded approaches is presented and reasons for their exclusion are analyzed.

Objectives: After defining the context, the objectives of this study are listed and grouped attending to four points:

- Identify the solutions that have been proposed to address the systematic or automatic generation of functional test cases from functional requirements described in informal languages.

- Analyze, with a set of indicators, if they offer a suitable solution for real projects and improve the test phase with the reduc- tion of cost and time and the coverage increase of functional test.

- Identify the gaps in current research.

- Propose future works about the automatic generation of functional test cases from functional requirements.

Methods: The search strategy for the review consists in three main stages:

- Find published surveys similar to the one used in this paper. Consequently, three previous surveys were found. The search started with approaches included in these papers and the analysis of those which covered the constraints defined.

- Design a Web-search to find other relevant and new approaches. Several sets of keywords were used by combining the start and end artifacts. Some examples are: "test, case, generation, requirement", "test case, use case", "system test case approach", etc. These sets were used both in specific and general search engines such as Google, Google Scholar, Scopus, EI Compendex, ISI Web of Knowledge, IEEEXplore, ACM Digital Library and CiteSeerX.

- Look into references of papers included in previous reviews.

Results: The final result of searching approaches (including all the references from previous surveys and new approaches found) was grouped in 24 approaches which are presented in Table 1.

This table includes 11 approaches (in grayed way) which have a little mismatch with the characteristics set up in the survey. When looking for related works, it is realized that there are some approaches which set out similar ideas to other approaches without introducing a new idea of valuable content. These approaches are not included in the characterization study of Section 4 , although the reasons for not analyzing them are specifically mentioned.

In the same way, some of the approaches included in Denger and Medina (2003), Gutiérrez et al. (2006) do not appear in this survey, either. Firstly, despite the reference it has been impossible to find a copy of some approaches included in Denger and Medina (2003), even asking their authors for them. In addition, some of them are no longer maintained. Secondly, there are some approaches in both surveys that do not match the criteria defined at the beginning of this section. For example, some approaches define test cases at a different level of detail than system test level, or some others use formal techniques to define requirements instead of natural languages.

\subsection{A characterization schema}

Although the approaches shown in Table 1 are described separately and offer a different level of depiction, they are, still, defined within the same context. In line with the definition of characterization schema, our next step in presenting the survey is to define a common pattern to depict in each approach. This schema enables the storage of information of every approach in a common pattern in order to make the comparison among them easier. This characterization schema solves the questions proposed in the survey in order to answer the main question of this research study: is it possible the automatic generation of test cases from functional requirements described in an informal way? These questions are

- Q1: Which are the main characteristics of the approach? We want to know if the approach offers a global vision in the survey, which its inputs are, how requirements are defined, etc.

- Q2: Does it offer suitable tools for support? Suitable tools for supporting the development are essential to demonstrate a real generation of test cases from functional requirements.

- Q3: How are test cases obtained? It is necessary to evaluate how test cases are obtained and presented as a result. 
Table 2

Characterization Schema for approach description in the survey.

\begin{tabular}{lll}
\hline Elements & Attributes & Dominion \\
\hline Technique & Inputs & $\{$ String+ $\}$ \\
& Format of the inputs & $\left\{\right.$ no, $\left.{ }^{*}\right\}$ \\
& Coverage criterion & $*$ \\
& Notation & $*$ High, Medium, Low $\}$ \\
Systematization degree & $\{$ Yes, no $\}$ \\
Tool & Test values definition & $*$ \\
& Tool name & $*$ \\
License & $\{$ Yes, no $\}$ \\
Test case & Available & $\{$ total, partial $\}$ \\
& Automation degree & $*$ \\
& Environment & $*$ \\
& Amount of test cases generated & $*$ \\
Format of test cases generated & $*$ \\
Benefits & $*$ \\
& Problems & $\{$ Yes, no $\}$ \\
& References to projects & $\{$ Paper, short paper, \\
& Format & inner report, book \\
& & chapter $\},\{$ journal, \\
& & proceedings, journal, \\
& & book $\}$ \\
& Size & (String +$\}$ \\
& References &
\end{tabular}

- Q4: Is the approach well-documented? Sometimes it is impossible to apply an appropriate approach because it is not well-documented.

Several indicators are selected to answer every question in each approach. They are described in Table 2 and the next paragraphs. Previous works, such as Denger and Medina (2003), Gutiérrez et al. (2006) (cited in Section 2), have been used as worthy sources of information to define elements, attributes and dominions of this characterization schema. The study of testing techniques cited in Vegas et al. (2009) has also been used as an additional source of information about characterization schemas.

In Table 2, each attribute is formalized by defining either the set of possible values (domain) or, in other cases, their format. Domains have been determined through a simplified and auto-explicative notation for regular expressions. Sometimes, it is necessary to allow a free text as a value for an attribute.

To delimit a domain for some fields has been an impossible task, due to the fact that they present a wide disparity of values. These attributes are marked with an "*” in Table 2. Domains between keys " $\{\ldots\}$ " define a set of options for the value of the attribute. There are some exceptions in the attributes Inputs and References. Both attributes are described with a list of strings. The domain for the attribute size is a number instead of a text string (as indicated in the table). Next paragraph provides a further description of the attributes in Table 2.

As seen in the preceding section and taking into consideration Table 2 above, we now turn to the depiction of each attribute and their corresponding elements. Firstly, we look at the Technique element which describes the test cases generation process which, in turn, answers to question Q1 and is composed of:

- Input. It offers the information needed for the process of generating test cases. Its domain consists in a list of strings with the needed artifacts.

- Format of the input. It determines how the input information must be defined. Its domain consists in a string which describes this format.

- Coverage criterion. It explains which is the testing technique used for generating test cases and so on, when the generation process is finished. This technique is highly based on the definition of the input requirements, for example, if one functional require- ment is defined as a state-chart, the coverage criterion may be covering all states or all transitions, but, if the functional requirement is defined as natural text, the coverage criterion may be encompassing all the possible scenarios.

- Notation. It analyzes the format used during the generation process such as state-machines or UML activity diagrams.

- Systematization degree. It measures the degree of formalism when defining the transformation process. Thus, a high systematization degree will allow the process to be applied as appeared in the documentation. However, a medium and, even, a low automation degree will imply that additional support and human personal decisions are needed in the process. Systematization degree also affects the repeatability of the process. A low degree implies a relevant human support. For this reason, two different persons may obtain different results from the same functional requirement.

- Test values definition. It describes if the information required for the test case is widely indicated by the approach.

The second group of indicators oriented to answer question Q2 is Tool. The Tool field group attributes indicate the degree of tool development to support each approach. For this reason, these attributes have only been evaluated in the approaches which cite or define a tool. They are as follows:

- Tool name. It describes the name of the tool and is a free field.

- Licenses. It puts forward information about tool licenses policies.

- Availability. It indicates the possibility of obtaining a copy of the tool from either the Web or the author.

- Automation degree. It measures the part of the process that has been implemented in the tool. That is, if the whole process has been implemented in the supporting tool or only a piece of the process is executed automatically.

- Environment. It describes the execution environment of the tool: operative system, libraries, etc.

Attributes grouped in Test Case describe the results obtained after applying the generation process. They try to answer Q3 and consist of the following:

- Amount of test cases generated. It offers a reference to the amount of test cases generated by the approach, depending on the used technique.

- Format of test cases generated. It indicates how the test cases are defined.

- Benefits. It studies the advantages detected in the generation process according to our own experience.

- Problems. It describes the most important disadvantages detected in our evaluation.

Finally, attributes for the element Documentation, which answers to question Q4, describe the documentation found about every approach. They are as follows:

- References to projects. It indicates if the documentation includes either references to real projects or empirical experiences, in cases where the approach was used.

- Format. It describes the format of the available documentation for the approach.

- Size. It analyzes the amount of documentation measured by the number of pages about the approach.

- References. It lists the most relevant references about each approach.

As it was the aim of this section, with this pattern we offer a homogeneous way to describe the approaches of study. The evaluation of these four elements and their specific attributes offer a wide 
Table 3

Characterization Schema for the Approach "Software Requirements and Acceptance Testing".

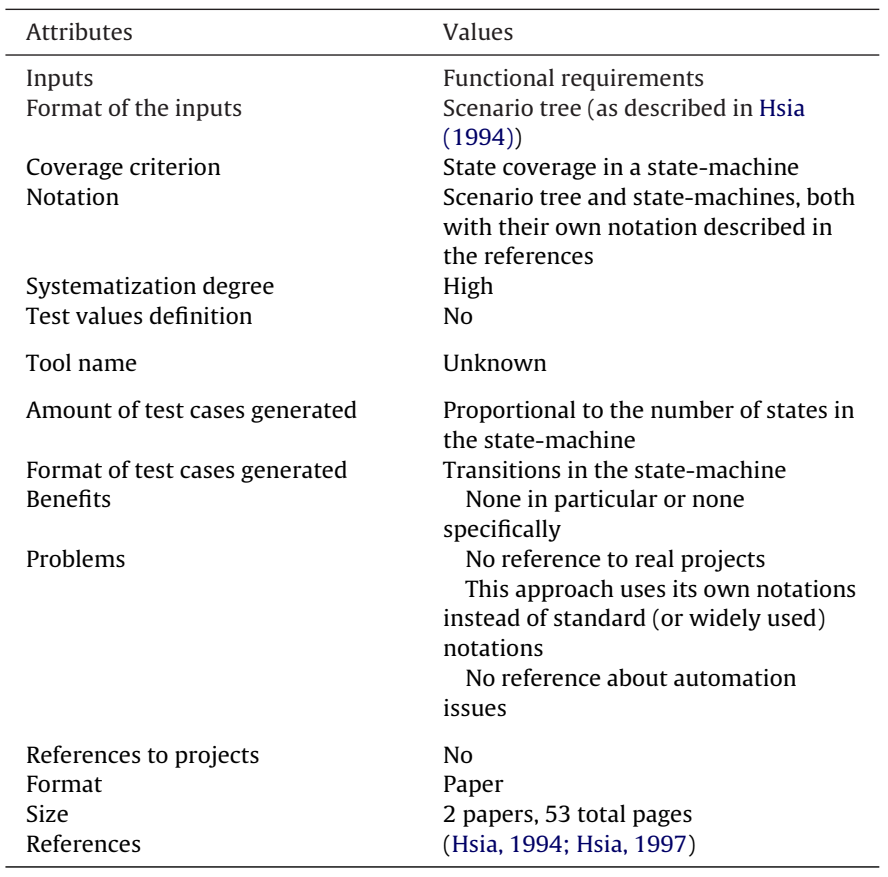

vision of each approach, essential for the conclusions presented at the end of the paper.

\section{Characterization of approaches}

Based on the characterization schema presented in Table 2, this section provides an instance of this schema for each approach numbered in Table 1. At the same time, each approach is presented with its most relevant references and a global description which is completed with its characterization in the common schema.

Nevertheless, a set of approaches of study numbered in Table 1 is not characterized in detail in this section, either because they do not include any new process or idea comparing them with the set of approaches characterized in next paragraphs or because they are not completely focused on the line of the paper. They are briefly presented at the end of this section.

\subsection{Software requirements and acceptance testing}

The approach for Software Requirements and Acceptance Testing, presented in Hsia (1994, 1997), focuses on the generation of acceptance test cases.

However, the scope of this acceptance test case is the same than the scope of functional system test case defined in previous sections, thus it was included in the survey.

The approach is divided into two parts: the first one describes a requirement elicitation process, mainly focused on functional requirements elicitation, with a specific model introduced by the approach based on Scenario tree. They are the input for the second part which describes the generation of test cases from these requirements. Table 3 shows the characterization schema for this approach.

\subsection{Testing object-oriented systems}

The approach presented in Binder (1999) adapts the CategoryPartition Method (Ostrand and Balcer, 1988) to a use case in natural language context. The starting point is the group of functional
Table 4

Characterization Schema for the approach "Testing Object-Oriented Systems".

\begin{tabular}{|c|c|}
\hline Attributes & Values \\
\hline Inputs & Functional requirement \\
\hline Format of the inputs & $\begin{array}{l}\text { Templates (the structure of the } \\
\text { template is not defined in the } \\
\text { approach) }\end{array}$ \\
\hline Coverage criterion & $\begin{array}{l}\text { All combinations for the operational } \\
\text { variables defined }\end{array}$ \\
\hline Notation & Tabular text \\
\hline Systematization degree & Low \\
\hline Test values definition & Yes \\
\hline Tool name & Unknown \\
\hline Amount of test cases generated & Satisfactions of a coverage degree \\
\hline Format of test cases generated & $\begin{array}{l}\text { Description of the values for } \\
\text { operational variables }\end{array}$ \\
\hline Benefits & $\begin{array}{l}\text { This approach offers a clear } \\
\text { reference of the starting date of the } \\
\text { testing process } \\
\text { This approach includes a reference to } \\
\text { the IEEE982.1 standard as a way of } \\
\text { measuring the coverage of the } \\
\text { generated test cases }\end{array}$ \\
\hline Problems & $\begin{array}{l}\text { The approach describes which } \\
\text { information must appear in an } \\
\text { extended requirement, although it } \\
\text { does not describe any template for the } \\
\text { requirements } \\
\text { The approach is fully based on } \\
\text { natural language, what makes its } \\
\text { automation highly difficult } \\
\text { The approach does not include } \\
\text { references to real applications }\end{array}$ \\
\hline References to projects & No \\
\hline Format & Book \\
\hline Size & 9 pages \\
\hline References & Binder (1999) \\
\hline
\end{tabular}

requirements written in natural language extended with operational variables. In this approach, an operational variable is a synonym of a category. For this reason, an operational variable is a variable factor whose value determines which scenario of a use case will be exercised in each moment. For example, if there is a use case with two scenarios for valid and invalid data, it is represented as an operational variable. At the end of the process, a table with all test cases for testing and operational variables is obtained.

Table 4 represents the characterization schema for this approach.

\subsection{Automated test case generation from dynamic models}

This approach, previously explained in Fröhlich and Link (1999, 2000), is divided into two blocks:

a. The first block describes how to translate a functional requirement in natural language into a state-chart diagram.

b. The second block describes how to generate a set of functional test cases from that state-chart diagram.

This second block is based on the language for problems planning called STRIPS (Fikes and Nilsson, 1971). The state-chart is translated into STRIPS operations, which change in the state of the system, and test cases are automatically generated from a planning tool, which supports STRIPS language. Table 5 displays the characterization schema for this approach. 
Table 5

Characterization Schema for the approach "Automated Test Case Generation from Dynamic Models".

\begin{tabular}{|c|c|}
\hline Attributes & Values \\
\hline Inputs & Functional requirements \\
\hline Format of the inputs & $\begin{array}{l}\text { Template (this approach does not } \\
\text { include the structure of the template, } \\
\text { however, it suggests to follow the } \\
\text { structure introduced in Cockburn } \\
(2000) \text { ) }\end{array}$ \\
\hline Coverage criterion & All states or all transitions \\
\hline Notation & UML state diagram \\
\hline Systematizations degree & High \\
\hline Test values definition & No \\
\hline Tool name & Any tool supporting STRIPS language \\
\hline Amount of test cases generated & $\begin{array}{l}\text { It depends on the coverage criterion } \\
\text { chosen }\end{array}$ \\
\hline Format of test cases generated & $\begin{array}{l}\text { Test cases are defined with pre and } \\
\text { post-conditions and sequence of } \\
\text { transitions }\end{array}$ \\
\hline Benefits & $\begin{array}{l}\text { This process may be applied with the } \\
\text { help of any tool supporting STRIPS } \\
\text { It includes a guide on how to } \\
\text { measure the coverage of the selected } \\
\text { test cases } \\
\text { The generation of the activity } \\
\text { diagram is described in a very } \\
\text { systematic way }\end{array}$ \\
\hline Problems & $\begin{array}{l}\text { The approach indicates how to } \\
\text { manage related functional } \\
\text { requirements. Nevertheless, this fact } \\
\text { implies creating state machines with } \\
\text { states which are, in turn, other state } \\
\text { machines and this fact raises up the } \\
\text { complexity } \\
\text { Although it is a very systematic } \\
\text { process, the state-machine is not } \\
\text { automatically generated and must be } \\
\text { performed by hand } \\
\text { The translation from the state-chart } \\
\text { into STRIPs operation is not automatic. } \\
\text { It is not fully systematic due to the } \\
\text { approach that allows the user to } \\
\text { include supplementary operations, } \\
\text { such as the ones related to test values }\end{array}$ \\
\hline References to projects & No \\
\hline Format & Paper \\
\hline Size & 2 papers, 40 total pages \\
\hline References & Fröhlich and Link $(1999,2000)$ \\
\hline
\end{tabular}

\subsection{Testing from use cases using path analysis technique}

The starting point of this approach, proposed by Naresh (2002), is a functional requirement written in natural language and formatted in tabular text. However, this approach does not indicate a template format or rules to define functional requirements, although it uses an ad-hoc example. In its development process, this approach translates a functional requirement into a flow diagram and performs a path coverage technique to generate test cases. The result of this process is a table with all the possible paths of execution extracted from the diagram and expressed in natural language. Table 6 shows the characterization schema for this approach.

\subsection{Generating test cases from use cases}

This process, proposed by Heumann (2002), begins with the definition of functional requirements without defining any specific model to describe them. Nonetheless, the approach lists the minimum elements necessary for a functional requirement to perform the generation process. The result of this approach is a table with the system test cases represented as usage scenarios also in nat-
Table 6

Characterization Schema for the approach "Testing from Use Cases using Path Analysis Techniques".

\begin{tabular}{|c|c|}
\hline Attributes & Values \\
\hline Inputs & Functional requirements \\
\hline Format of the inputs & $\begin{array}{l}\text { Template. This approach does not } \\
\text { indicate any format }\end{array}$ \\
\hline Coverage criterion & All paths from a flow diagram \\
\hline Notation & Own notation for flow diagrams \\
\hline Systematization degree & Low \\
\hline Test values definition & $\begin{array}{l}\text { No (it is cited in the approach, but it } \\
\text { does not describe how to manage tests } \\
\text { values) }\end{array}$ \\
\hline Tool name & Unknown \\
\hline Amount of test cases generated & $\begin{array}{l}\text { Number of different paths from the } \\
\text { flow diagram }\end{array}$ \\
\hline Format of test cases generated & $\begin{array}{l}\text { Descriptions of the steps from the test } \\
\text { case }\end{array}$ \\
\hline Benefits & $\begin{array}{l}\text { It offers a guide on how to measure } \\
\text { paths and how to detect low-value } \\
\text { path that may be omitted } \\
\text { Includes a step-by-step example }\end{array}$ \\
\hline Problems & $\begin{array}{l}\text { Many parts of the process are } \\
\text { performed using natural language, } \\
\text { what makes its automation highly } \\
\text { difficult } \\
\text { The approach does not indicate how } \\
\text { to generate test cases from } \\
\text { requirements that depend on other } \\
\text { requirements } \\
\text { It does not indicate how to select and } \\
\text { quantify the attributes used for } \\
\text { measuring the relevance of a path }\end{array}$ \\
\hline References to projects & No \\
\hline Format & Paper \\
\hline Size & 1 Paper, 20 total pages \\
\hline References & Naresh (2002) \\
\hline
\end{tabular}

ural language. Table 7 shows the characterization schema for this approach.

\subsection{Quality web systems}

As previous approaches, Dustin (2002) starts the process with the requirement elicitation process that includes functional requirements and some others like feasibility or accessibility requirements. Due to the fact that this approach focuses on Web systems, its process may be easily applied to other types of systems. As described in the approach, it sets out from the functional requirements written in some specific templates. The results are system functional test cases defined in natural language by using a template also specified in the proposal. Table 8 presents its characterization schema.

\subsection{Scenario-based validation and test of software}

SCENT (Ryser and Glinz, 2003) is a scenario-based approach to elicit, validate and verify functional requirements. It also includes a process for generating test cases from the scenarios. For this reason, this approach may be divided into two blocks:

a. The first one describes how to create and define scenarios.

b. The second block explains how to generate test cases.

The generation approach starts from a set of use case scenarios defined in natural language by using a specific template proposed in the approach. The results are a set of test cases to validate scenarios defined in tables and in natural language. 
Table 7

Characterization Schema for the approach "Generating test cases from use cases".

\begin{tabular}{|c|c|}
\hline Attributes & Values \\
\hline Inputs & Functional requirement \\
\hline Format of the inputs & Text template \\
\hline Coverage criterion & All scenarios \\
\hline Notation & Ad-Hoc \\
\hline Systematization degree & Low \\
\hline Test values definition & No \\
\hline Tool name & Unknown \\
\hline Amount of test cases generated & $\begin{array}{l}\text { Number of scenarios from the } \\
\text { functional requirement }\end{array}$ \\
\hline Format of test cases generated & $\begin{array}{l}\text { Textual descriptions of the steps of a } \\
\text { test case }\end{array}$ \\
\hline Benefits & None specifically \\
\hline Problems & $\begin{array}{l}\text { It is an approach designed to treat } \\
\text { the functional requirements } \\
\text { independently. It cannot offer } \\
\text { dependencies among functional } \\
\text { requirements } \\
\text { It is very difficult to automate } \\
\text { because it is based on natural language } \\
\text { To identify all its possible } \\
\text { combinations may result a hard task in } \\
\text { cases of complex functional } \\
\text { requirements }\end{array}$ \\
\hline References to projects & No \\
\hline Format & Paper \\
\hline Size & 1 document, 10 pages \\
\hline References & Heumann (2002) \\
\hline
\end{tabular}

This approach is illustrated with a real application in two real projects which are documented in Itschner et al. (1998). Table 9 represents the characterization schema for this approach.

\section{Table 8}

Characterization Schema for the approach "Quality Web Systems".

\begin{tabular}{|c|c|}
\hline Attributes & Values \\
\hline Inputs & Functional requirements \\
\hline Format of the inputs & $\begin{array}{l}\text { Own templates defined by the } \\
\text { approach }\end{array}$ \\
\hline Coverage criterion & $\begin{array}{l}\text { It is a heuristic criteria, an engineer } \\
\text { should value if there are enough } \\
\text { scenarios and test values }\end{array}$ \\
\hline Notation & No \\
\hline Systematization degree & Medium \\
\hline Test values definition & Yes \\
\hline Tool name & Unknown \\
\hline Amount of test cases generated & $\begin{array}{l}\text { It depends on the number of scenarios } \\
\text { and test values available }\end{array}$ \\
\hline $\begin{array}{l}\text { Format of test cases generated } \\
\text { Benefits }\end{array}$ & $\begin{array}{l}\text { Test cases are defined as a text pattern } \\
\text { It proposes a specific template for } \\
\text { test cases }\end{array}$ \\
\hline & $\begin{array}{l}\text { There is no direct correspondence } \\
\text { between a test pattern and a functional } \\
\text { requirement. The same test pattern can } \\
\text { include a test case referenced to } \\
\text { several use cases }\end{array}$ \\
\hline Problems & $\begin{array}{l}\text { The approach is based on its own } \\
\text { definition of functional requirements. } \\
\text { It can only be applied if requirements } \\
\text { are grouped according to the approach }\end{array}$ \\
\hline References to projects & No \\
\hline Format & Section in a book chapter \\
\hline Size & 13 pages \\
\hline References & Dustin (2002) \\
\hline
\end{tabular}

Table 9

Characterization Schema for the approach "SCENT".

\begin{tabular}{|c|c|}
\hline Attributes & Values \\
\hline Inputs & $\begin{array}{l}\text { Functional requirements defined as } \\
\text { scenarios according to Ryser and Glinz } \\
\text { (2003) }\end{array}$ \\
\hline Format of the inputs & Scenarios templates \\
\hline Coverage criterion & Each node and transition \\
\hline Notation & $\begin{array}{l}\text { State diagrams and dependency } \\
\text { diagrams with its own notation }\end{array}$ \\
\hline Systematization degree & Low \\
\hline Test values definition & No \\
\hline Tool name & Unknown \\
\hline Amount of test cases generated & Alternative states of a scenario \\
\hline $\begin{array}{l}\text { Format of test cases generated } \\
\text { Benefits }\end{array}$ & $\begin{array}{l}\text { They are rows in a table } \\
\text { It offers practical examples and } \\
\text { enterprise applications } \\
\text { It enables the verification of the } \\
\text { behavior of a functional requirement } \\
\text { including its dependencies with other } \\
\text { functional requirements }\end{array}$ \\
\hline Problems & $\begin{array}{l}\text { Although the approach offers a } \\
\text { complete definition of scenarios, test } \\
\text { generation description is not } \\
\text { sufficiently detailed } \\
\text { SCENT defines some steps in a very } \\
\text { informal way without specific } \\
\text { guidelines to apply them. It is quite } \\
\text { negative for automatic generation } \\
\text { Although it can be automatic, several } \\
\text { elements depend on engineers' } \\
\text { experiences and decisions and require } \\
\text { a manual process }\end{array}$ \\
\hline References to projects & Yes. Itschner et al. (1998) \\
\hline Format & Paper \\
\hline Size & $\begin{array}{l}2 \text { documents, } 123 \text { pages and a specific } \\
\text { document with practical examples }\end{array}$ \\
\hline References & Ryser and Glinz (2003) \\
\hline
\end{tabular}

\subsection{Requirement-based testing}

This approach, whose characterization schema is presented in Table 10, was proposed by Mogyorodi (2003) and it is also divided into two parts with 12 steps. The first part (steps from 1 to 4 ) starts with the formal revision of a set of requirements described in natural language. This revision is executed by a set of experts who check if requirements agree with general objectives. The second one explains how to generate test cases; all requirements are described with a cause-effect diagram and test cases are generated from this diagram (steps 5 and 6). A detailed example is presented in Mogyorodi (2001), although this paper does not offer a specific description about the automation of the processes, which depends on the expert's experience. These diagrams are translated into a decision table with different combinations which are mixed to select each test case. Later on, from steps 7 to 12 , they are reviewed and checked with users. This approach neither defines nor cites any format for the input functional requirements. It results in a set of functional test cases in natural language. A test case is composed of a set of causes and its subsequent effects.

This approach offers a tool named CaliberRBT, although it is not available for downloaded.

\subsection{Traceability from use cases to test cases}

This approach, proposed by IBM, is not in fact an approach. This paper presents a tool, named IBM Rational RequisitePro, which defines a set of functional requirements, presented as use cases and described by means of activity diagrams and natural languages. This tool also defines test cases and offers a set of traceability matrix 
Table 10

Characterization Schema for the approach "Requirements-based testing".

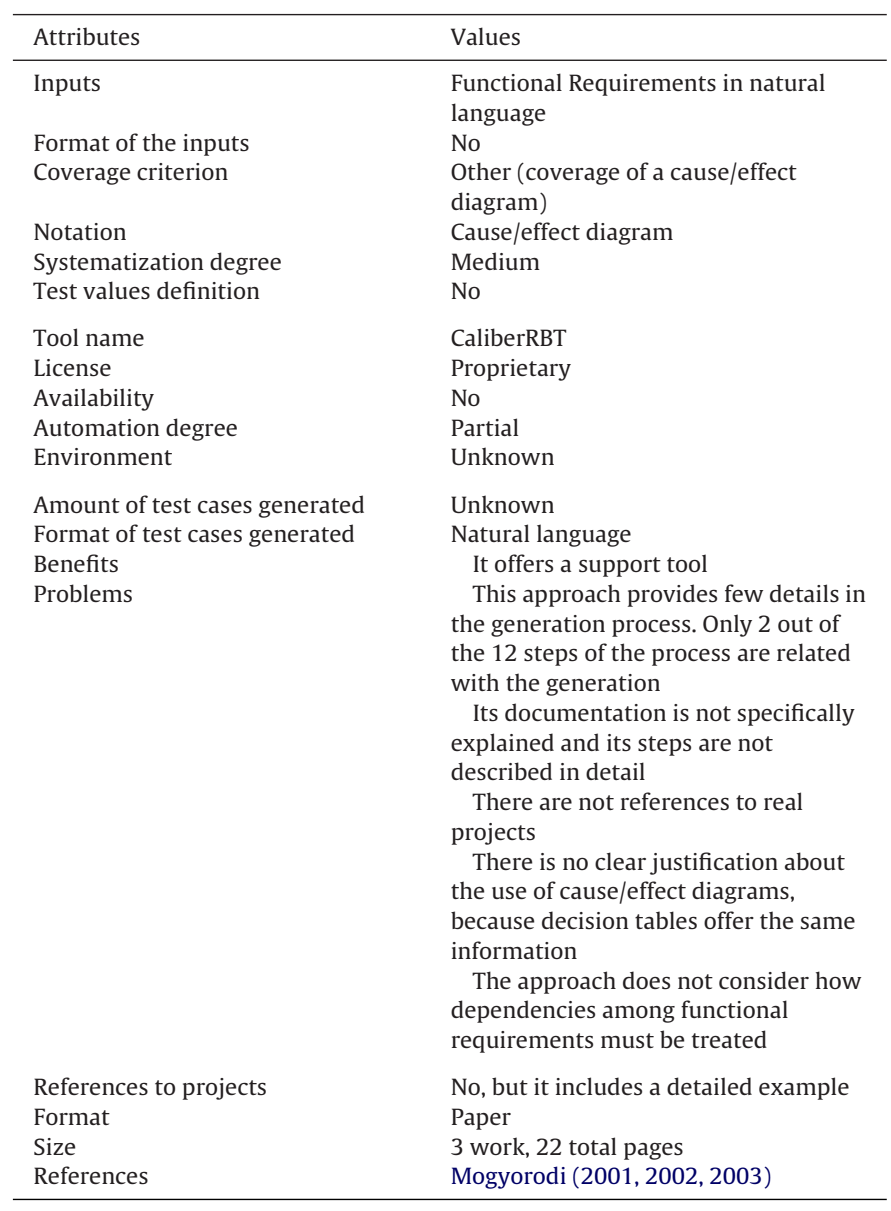

to connect each scenario of a functional requirement with its test cases. Despite the fact that it is not an approach (Zielczynski, 2006), it was included on the paper because it offers a detailed explanation about the definition of different scenarios from a use case. It also adds how to generate, manually, test cases from them. Table 11 presents its characterization schema.

\subsection{RETNA: from requirements to testing in natural way}

The approach "RETNA", proposed in Boddu et al. (2004), is divided into two blocks:

a. The first block describes a natural language analyzer. This analyzer is used for the study of functional requirements written in a paragraph no longer than 399 characters. After the analysis, the process continues with the elaboration of a state machine which is obtained in MONA language.

b. The second block of the approach describes how to generate functional test cases from the state machine. It introduces several constraints with the natural language analyzer. In fact, no tabular text or template may be used.

Table 12 presents its characterization schema.

\subsection{A UML-based test generation and execution}

Once again, this approach presented by Ruder (2004), starts with functional requirements written in natural language. The result is a set of functional test cases obtained from a coverage criterion based on combinations that support boolean propositions defined
Table 11

Characterization Schema for the approach "Traceability from Use Cases to Test Cases".

\begin{tabular}{ll}
\hline Attributes & Values \\
\hline Inputs & Functional Requirements in \\
& RequisitePro \\
Format of the inputs & Scenarios in RequisitePro \\
Coverage criterion & Coverage of Scenarios \\
Notation & Activity diagrams \\
Systematization degree & Low \\
Test values definition & Yes \\
Tool name & RequisitePro \\
License & Proprietary \\
Availability & No \\
Automation degree & Partial \\
Environment & Microsoft Windows Operating System \\
Amount of test cases generated & Depends on the tester selection \\
Format of test cases generated & Scenarios in RequisitePro \\
Benefits & It offers a support tool \\
& It provides a commercial solution \\
Problems & used in companies \\
Iize & It is not an approach \\
References & It is completely closed to \\
& RequisitePro \\
& The test case generation depends on \\
References to projects & the tester and it is completely manual \\
& No \\
& Paper and handbooks of the tool \\
& Z 21-page paper and handbooks \\
& \\
\hline &
\end{tabular}

in Test Specification Language (TSL) (Balcer et al., 1990). TSL is a language used for writing format test specifications of the functions of a software system. This language defines the Category-Partition Method in Ostrand's paper.

Table 12

Characterization Schema for the approach "RETNA".

\begin{tabular}{|c|c|}
\hline Attributes & Values \\
\hline Inputs & $\begin{array}{l}\text { Functional requirements described } \\
\text { with a single paragraph no longer than } \\
399 \text { characters }\end{array}$ \\
\hline Format of the inputs & No \\
\hline Coverage criterion & Scenarios (coverage of a state diagram) \\
\hline Notation & State-diagram (MONA notation) \\
\hline Systematization degree & High \\
\hline Test values definition & No \\
\hline Tool name & $\begin{array}{l}\text { No (it is a set of scripts in different } \\
\text { languages that using different libraries }\end{array}$ \\
\hline License & Proprietary \\
\hline Availability & No \\
\hline Automation degree & Total \\
\hline Environment & Unknown \\
\hline Amount of test cases generated & $\begin{array}{l}\text { Coverage criteria up in the state } \\
\text { diagram }\end{array}$ \\
\hline Format of test cases generated & It is not detailed in the approach \\
\hline Benefits & $\begin{array}{l}\text { The process to obtain a set of test } \\
\text { cases from functional requirements in } \\
\text { natural language is completely } \\
\text { automatic }\end{array}$ \\
\hline Problems & $\begin{array}{l}\text { Obtained results are not detailed } \\
\text { enough and there are no examples on } \\
\text { how state diagrams are obtained } \\
\text { It is based on a natural language } \\
\text { analyzer, thus, it can only be used with } \\
\text { requirements written in English }\end{array}$ \\
\hline References to projects & No \\
\hline Format & Paper \\
\hline Size & 9 pages \\
\hline References & Boddu et al. (2004) \\
\hline
\end{tabular}


Table 13

Characterization Schema for the approach "A UML-based test generation and execution".

\begin{tabular}{|c|c|}
\hline Attributes & Values \\
\hline Inputs & $\begin{array}{l}\text { Requirements written in natural } \\
\text { language }\end{array}$ \\
\hline Format of the inputs & $\begin{array}{l}\text { Functional requirements with tabular } \\
\text { structure }\end{array}$ \\
\hline Coverage criterion & $\begin{array}{l}\text { Other (combination that support } \\
\text { boolean propositions defined by TSL } \\
\text { Language) }\end{array}$ \\
\hline Notation & $\begin{array}{l}\text { Activity diagrams described with } \\
\text { stereotypes, categories and partitions }\end{array}$ \\
\hline Systematization degree & Medium \\
\hline Test values definition & Yes \\
\hline Tool name & TDE-UML \\
\hline License & Proprietary \\
\hline Availability & No \\
\hline Automation degree & Medium \\
\hline Environment & Unknown \\
\hline Amount of test cases generated & $\begin{array}{l}\text { Depends on different alternatives and } \\
\text { paths in the activity diagram }\end{array}$ \\
\hline Format of test cases generated & $\begin{array}{l}\text { Paths and a set of partitions (they can } \\
\text { be defined with a set of test scripts) }\end{array}$ \\
\hline Benefits & $\begin{array}{l}\text { The use of stereotypes permits to } \\
\text { add information to automate the test } \\
\text { generation process under UML rules } \\
\text { It groups two techniques to test } \\
\text { definition }\end{array}$ \\
\hline Problems & $\begin{array}{l}\text { It focuses on graphical interfaces. } \\
\text { Consequently, it does not permit test } \\
\text { generation for other kind of external } \\
\text { interfaces of a system, for example, } \\
\text { two systems communication } \\
\text { It does not describe the in-depth } \\
\text { process of building activity diagrams } \\
\text { It does not clarify whether each } \\
\text { functional requirement needs an } \\
\text { activity diagram or only one activity } \\
\text { diagram is required for the whole } \\
\text { system } \\
\text { We could not find an available } \\
\text { version of the tool to test it }\end{array}$ \\
\hline References to projects & No \\
\hline Format & Paper \\
\hline Size & 1 papers, 20 pages \\
\hline References & Ruder (2004) \\
\hline
\end{tabular}

The approach claims that these test cases may be executed in tools that interact with graphical interfaces, which allows to automate test cases execution. They use a set of heterogeneous tools and scripts ad-hoc that are not now available on the Web. Some of them are: JTrek to test oracles definition, MONA languages and a tool to translate formulae into state-machines.

Table 13 shows the characterization schema for this approach.

\subsection{An automatic tool for generating test cases from the system's requirements}

One of the most relevant aspects of this approach included in Ibrahim et al. (2007), Ismail et al. (2007) is that it introduces a tool, called GenTCase, for generating test cases automatically. The process starts with the definition of use case diagram which is supported by the tool. Every use case may be completed with some event flow that contains a tabular description of the steps of a use case in natural language, including preconditions, post-conditions, alternative steps and a UML sequence diagram. After the analysis of different paths, the generation results in a text file with the generated test cases. Due to the references found, the tool is described instead of the process, thus it may be concluded that the process is the tool
Table 14

Characterization Schema for the approach "An automatic tool for generation test cases from the system's requirements".

\begin{tabular}{|c|c|}
\hline Attributes & Values \\
\hline Inputs & $\begin{array}{l}\text { None. Requirements are defined with } \\
\text { the own tool }\end{array}$ \\
\hline Format of the inputs & Not applicable \\
\hline Coverage criterion & $\begin{array}{l}\text { A combination of main steps and } \\
\text { alternative steps }\end{array}$ \\
\hline Notation & $\begin{array}{l}\text { UML functional requirements diagrams } \\
\text { like use cases, sequences diagrams and } \\
\text { tabular text }\end{array}$ \\
\hline Systematization degree & High \\
\hline Test values definition & No \\
\hline Tool name & GenTCase \\
\hline License & Unknown \\
\hline Availability & No \\
\hline Automation degree & Total \\
\hline Environment & Microsoft Windows Operating System \\
\hline Amount of test cases generated & Depends on alterative steps \\
\hline Format of test cases generated & Textual description of test steps \\
\hline Benefits & A tool to support the process \\
\hline Problems & $\begin{array}{l}\text { It does not offer a theoretical base, } \\
\text { the approach is the tool } \\
\text { It could be redundant because an } \\
\text { execution flow and a sequence diagram } \\
\text { have to be defined at the same time. In } \\
\text { references, the use of this sequence } \\
\text { diagram for test generation is not clear }\end{array}$ \\
\hline References to projects & No \\
\hline Format & 2 Papers \\
\hline Size & 20 Total pages \\
\hline References & $\begin{array}{l}\text { Ibrahim et al. (2007), Ismail et al. } \\
\text { (2007) }\end{array}$ \\
\hline
\end{tabular}

in itself. Table 14 shows the characterization schema for this approach.

\subsection{Test cases generation from use cases}

This approach represents in our study a general tendency to the use of models in the test phase. This tendency, named model-based testing (MBT) (Legeard and Model-based Testing:, 2010), has been widely used in different areas of software testing. For instance, the approach MODEST (Rutherford and Wolf, 2003) starts with a domain model, described in XML, and generates a test code. Our survey includes three approaches on MBT environment quite close to the survey aims. Nevertheless, the only study in detail is the one presented by Gutierrez et al.; the two left are described in the next section.

Gutierrez et al.'s approach enriches the MBT with the use of the model-driven paradigm for the systematic generation of test cases from functional requirements represented as use cases. The approach is based on the UML Testing profile for this aim and is supported by a set of tools. The metamodels used are described in Gutiérrez et al. (2008a), but transformations are not included in edited papers, with the exception of a part of them that appears in Gutierrez et al.(2008b). However, the approach is included in a freeavailable tool named NDT-Suite. NDT-Suite is a tool case designed to support a methodology, named NDT (Navigational Development Techniques) (Escalona and Aragón, 2008), which is led to Web Engineering. This methodology is being widely used in real projects. Besides, the approach presents an automatic generation of test cases from use cases described by means of scenarios or activity diagrams. In www.iwt2.org a video with its use is available to download. Table 15 introduces its characterization schema. 
Table 15

Characterization Schema for the approach "Test cases generation from use cases".

\begin{tabular}{|c|c|}
\hline Attributes & Values \\
\hline Inputs & $\begin{array}{l}\text { Requirements described either as a } \\
\text { specific linguistic pattern or an activity } \\
\text { diagram }\end{array}$ \\
\hline Format of the inputs & $\begin{array}{l}\text { It offers its own linguistic patterns or a } \\
\text { specific extension of UML activity } \\
\text { diagrams to describe functional } \\
\text { requirements }\end{array}$ \\
\hline Coverage criterion & $\begin{array}{l}\text { A combination of main steps and } \\
\text { alternative steps }\end{array}$ \\
\hline Notation & $\begin{array}{l}\text { UML functional requirements diagrams } \\
\text { like use cases, sequences diagrams and } \\
\text { tabular text }\end{array}$ \\
\hline Systematization degree & High \\
\hline Test values definition & Yes \\
\hline Tool name & NDT-Suite \\
\hline License & $\begin{array}{l}\text { Free, although the Website defines the } \\
\text { profile over Enterprise Architect, } \\
\text { which is a non-free tool }\end{array}$ \\
\hline Availability & Yes \\
\hline Automation degree & Total \\
\hline Environment & Microsoft Windows Operating System \\
\hline Amount of test cases generated & Depends on alternative steps \\
\hline Format of test cases generated & $\begin{array}{l}\text { Textual description of test steps or } \\
\text { graphical presentation as an UML } \\
\text { diagram }\end{array}$ \\
\hline Benefits & $\begin{array}{l}\text { It is a tool to support the process } \\
\text { It is used by several companies } \\
\text { It is integrated in a framework for } \\
\text { the development of Web systems } \\
\text { It offers a large number of examples, } \\
\text { videos, etc }\end{array}$ \\
\hline Problems & $\begin{array}{l}\text { Transformations are not completely } \\
\text { published } \\
\text { Its documentation is mainly in } \\
\text { Spanish } \\
\text { Data to be put to the test must be } \\
\text { included manually }\end{array}$ \\
\hline References to projects & Yes \\
\hline Format & 2 Papers and a Website to support \\
\hline Size & 12 Total pages \\
\hline References & Gutiérrez et al. (2008a,b) \\
\hline
\end{tabular}

\subsection{Other related approaches}

As introduced at the beginning, there are several approaches in Table 1 that are not described in detail in previous sections. It mainly happened for two reasons:a. On one hand, some approaches are either quite similar to the newest one or they are extended by the newest approaches. This is the case of the following three:

- First, the book Writing Effective Use Cases (Cockburn, 2000) includes a chapter about generation of functional system test cases from functional requirements. This chapter proposes identifying every possible scenario from the use case and using them as test cases. This strategy is widely applied in the characterized approaches (for example in Heumann (2002) and Naresh (2002)) and the inclusion of this approach does not offer any new visions with regard to the newest one, which offers other new ideas apart from the scenario identification.

- Second, the approach named in Table 1 as Test Cases Generation from UML State Diagrams included in Kim et al. (1999) applied ideas quite similar to other approaches in the survey. From state diagrams, it generates a set of test cases that cover a set of paths of the state diagram. There are some current approaches that also offer this solution.

- Finally, the work by Wood and Reis (Use Cased derived Test Cases) (Wood and Reis, 2002) also sets out the same strategy to gen- erate test cases and, once again, it does not encompass more information than other similar approaches.

b. On the other hand, another reason for not describing an approach deeply is that it does not completely match with the aims of the paper. Some of them are listed below:

- The Category-Partition Method (Ostrand and Balcer, 1988) does not match with the aims of this paper, even though it was included because several of the presented approaches (as it was previously introduced in Section 4) use it for its generation methods.

- The next approach chronologically presented is TOTEM (Labiche and Briand, 2002) which is organized into two parts:

a. The first part describes how to generate test cases with exercise sequences of functional requirements by using parameters for the functional requirements in a similar manner to Requirement Based Contract.

b. The second part generates test cases for each functional requirement. However, this approach starts from UML sequence diagrams instead of text templates.

- After TOTEM, the next approach is defined in Riebisch et al. (2002) and Huebner et al. (2003) (Statistical Usage Testing Based on UML). Both works describe a process to generate statistical test cases from functional requirements defined as tabular text. Although statistical test cases may also be included in a system test level, they are different from functional test cases. The main objective of a statistical test case is not to identify the right implementation of a functional requirement, but to verify the feasibility defined in the requirements. The process begins with creating a state-chart diagram annotating each transition with a percentage that indicates the probability of execution of that transition. For example, if an S state has two outcoming transitions, S1 with 30\% and S2 with 70\%, this means that 3 out of 10 times that this state is reached, the transition S1 will be fired, and 7 out of 10 times, the transition S2 will be fired. Finally, test cases are defined with random paths over the state machine. According to this representative example, if 100 test cases are randomly generated, about 30 of them should execute the transition S1 and 70 of them should execute the transition S2 approximately.

- The approach Product Lines Use case Test Optimization (PLUTO), proposed by (Bertolino and Gnesi, 2003) and (Hsia, 1994), sets out a process to generate test cases for the functional requirements of product lines. This approach starts with functional requirements for products lines as described in Bertolino (2002). The notation for the functional requirements is the approach stated in the book (Cockburn, 2000) plus a new element called variability point, which describes the concrete characteristics of each product in the family. The result of this approach is both, a set of test cases common to all the products in the family and a different set of test cases specific for each product in the family. These test cases are described through templates in natural language and defined within the approach.

- PLUTO is another application of the Category-Partition Method, similar to other characterized approaches like (Binder, 1999) in Section 4.2. The main difference of PLUTO is that the categories are the variability point of the product family.

- A quite younger approach considered in this list is Automatic Test Generation: A Use Case Driven Approach, proposed by Nebut and Fleurey (2003), Nebut et al. (2006). This approach is divided into two parts:

1. The first one describes how to extend the UML use cases with contracts which are defined in a logic propositional language 


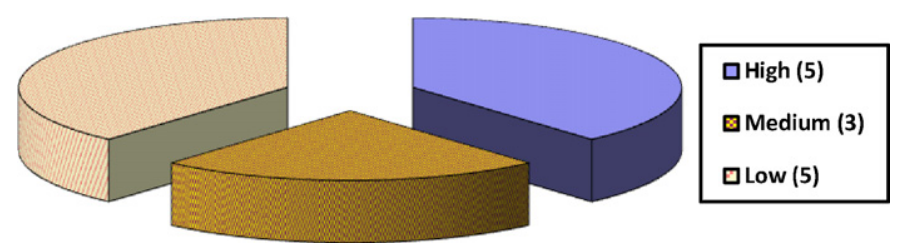

Fig. 1. Systematization degree.

determined in the own approach. The language is used to define preconditions, post-conditions and input parameters for the use case.

2. The second part describes the way to generate test cases from the extended UML use cases in an automatic way. Reference (Nebut and Fleurey, 2003) describes the application of this approach to product families and in Nebut et al. (2006) this approach is extended to generate test cases based on the behavior of each functional requirement.

It is similar to TOTEM because neither TOTEM nor Nebut's approach include objectives oriented to test cases generation from functional requirements. Both generate test cases from correct execution sequences in use cases, and, even though both of them are interesting, they are not close to the studied approaches.

- Another relevant approach within this group is REED (Oh et al., 2008) which generates test cases from a single requirement. Nevertheless, it is not included on the paper because, in fact, it is not an approach, but a tool to represent requirements in a specific notation and generate test case. The tool is close to this own representation and it does not focus on functional requirements.

In the environment of the model-driven testing, two approaches were referenced in Fig. 1, but they are not included in the paper either:

- The first one, by Pérez et al. (2009), is not widely described because it completely focuses on product lines. It uses the modeldriven paradigm for the systematic generation of test cases in product lines described with a dynamic model. Despite the fact that some ideas of the approach, like the systematic generation of test cases, are closely linked to the final goal of this paper, it is not focused on functional requirements.

- The second one, by Robles et al. (2009), is a model-driven approach that begins with a set of requirements, described by means of some mockups, generates user interfaces from them and, simultaneously, a set of tests to prove them. The approach uses XML to describe the system.

The use of the model-driven engineering in test generation is a new tendency that is solving the automatic, or, at least, systematic generation of test cases, as it is presented in final conclusions.

\section{Analysis}

With the previous overview of the state of art and with the definition of the characterization schema for each approach, this section points out the level of maturity in the generation of system test cases from functional requirements.

\subsection{Test generation strategy}

A first aspect to be taken into consideration to group approaches that may be extracted from the existing ones is the test generation strategy. There are two clear strategies: scenario analysis and test
Table 16

Test generation strategy in each approach.

\begin{tabular}{lll}
\hline Approach & $\begin{array}{l}\text { Category- } \\
\text { Partition } \\
\text { method }\end{array}$ & $\begin{array}{l}\text { Scenario } \\
\text { Analysis }\end{array}$ \\
\hline $\begin{array}{l}\text { Software Requirements and } \\
\text { Acceptance Testing (1997) }\end{array}$ & 1 & 1 \\
$\begin{array}{l}\text { Testing Object-Oriented Systems } \\
\text { (1999) }\end{array}$ & 1 & \\
Automated Test Case Generation from & & \\
$\begin{array}{l}\text { Dynamic Models (2000) } \\
\text { Testing From Use Cases Using Path }\end{array}$ & 1 & \\
$\begin{array}{l}\text { Analysis Technique (2002) } \\
\text { Generating Test Cases From Use Cases }\end{array}$ & 1 & \\
$\begin{array}{l}\text { (2002) } \\
\text { Quality Web Systems (2002) }\end{array}$ & 1 & \\
$\begin{array}{l}\text { SCENT (2003) } \\
\text { Requirement Based Testing (2003) }\end{array}$ & 1 & \\
Traceability from Use Case to Test & 1 & \\
Cases (2003) & 1 & \\
RETNA (2004) & & \\
A UML Based Test Generation and & 1 & \\
Execution (2004) & 1 & \\
An Automatic Tool for Generating Test \\
Cases from the System's Requirements
\end{tabular}

value analysis. With a total of 13 characterized approaches, 11 of them work with test value strategy, mainly based on the CategoryPartition method. There is only 1 that is dealing with scenario analysis, and another one that supports both strategies. Table 16 provides that information.

As observed in the table, most of the approaches work with the identification of usage scenarios from a functional requirement. This identification may be performed either directly over the functional requirement or by representing the functional requirement on a diagram (for example a state-chart diagram) firstly and, then, by using a coverage criterion over the diagram, like all states, all transitions, etc. There are few of them that use the analysis of test cases (based on the Category-Partition method, aforementioned). Only one of the approaches (A UML Based test generation and Execution) uses both strategies.

\subsection{The grade of systematization}

Another relevant attribute is the systematization degree of the approaches. Fig. 1 shows an abstract of the automation degree.

Functional requirements in natural languages are generic and informal artifacts. However, Fig. 1 confirms the possibility of developing a systematic and precise set of steps or tasks to generate functional test cases. Specifically, five out of all the analyzed approaches have become highly systematized. It may also be relevant when comparing the degree of systematization with the existence of a supporting tool for the approaches analyzed. Table 17 enumerates a list of the systematization degree and the inclusion of a tool obtained from these fields in the characterization schema.

As can be concluded, columns 2 and 3 are a mismatch within Table 17. Some of the approaches with a high degree of systematization do not offer a tool support. They are analyzed with the next factor.

It is important to stick out the lack of free and wide availability of the supporting tools in general in the approaches, as it can be deduced from their characterization tables. As aforementioned in Section 5.3, this tendency of changing approaches oriented to MBT was based on UML profiles. The use of UML-based tool is opening 
Table 17

Systematization degree and tools.

\begin{tabular}{lll}
\hline Approach & Systematization & Tool \\
\hline $\begin{array}{l}\text { Software Requirements and } \\
\text { Acceptance Testing }\end{array}$ & High & No \\
$\begin{array}{l}\text { Testing Object-Oriented Systems } \\
\text { Automated Test Case Generation from }\end{array}$ & Low & No \\
$\begin{array}{l}\text { Dynamic Models } \\
\text { Testing From Use Cases Using Path }\end{array}$ & Low & Yes (Partial) \\
$\begin{array}{l}\text { Analysis Technique } \\
\text { Generating Test Cases From Use Cases }\end{array}$ & Low & No \\
$\begin{array}{l}\text { Quality Web Systems } \\
\begin{array}{l}\text { Requirement Based Testing } \\
\text { Traceability from Use Case to Test }\end{array}\end{array}$ & Medium & No \\
$\begin{array}{l}\text { Cases } \\
\text { RETNA }\end{array}$ & Medium & No \\
$\begin{array}{l}\text { A UML Based Test Generation and } \\
\text { Execution }\end{array}$ & High & No \\
$\begin{array}{l}\text { An Automatic Tool for Generating Test } \\
\text { Cases from the System's Requirements } \\
\text { Test Cases Generation from Use Cases }\end{array}$ & Medium & Yes (partial) \\
\hline
\end{tabular}

a new path to offer suitable tools in order to support test cases definition and connection.

\subsection{Functional requirements models}

Closer to the systematization degree is the fact that some approaches work directly with functional requirement defined as use cases in natural language, but other approaches build a more formal model, as a first phase for generating functional test cases. A brief list on these approaches may be found in Table 18 . The first row presents approaches that deal with requirements in natural languages and the second one includes approaches that generate an intermediate model. This information is directly obtained from "format of the inputs" in the characterization schema.

Looking at the previous table, it may be concluded that a high number of approaches develop a model instead of directly working with the functional requirements in natural language. Even more, all the approaches which have a high degree of systematization (Fig. 1) include a formalization of the requirements into some kind of more formal model. As it has been checked in characterization schemas, the step for generating a more formal model from a functional requirement in natural text may also be described with a high degree of systematization. As a complement to Table 18 , Table 19 lists the notations and languages used in the analyzed approaches for generating a more formal representation of the requirements. This detail is not implicitly included in the characterization schema but it is mentioned in the description of each approach in the survey.

It may be observed that there is a wide range of notations. However, state-machines, activity diagrams and flow diagrams are quite similar. In fact, the whole UML introduces the activity diagram as a specialization of a state-chart and they both share many elements and semantics. Thus, the state diagram notation is then the notation frequently used, since seven of the approaches make use of it or of a similar one, for that matter. The three remaining approaches

\section{Table 18}

The use of formal models for requirements in test generation process

\begin{tabular}{lc}
\hline & Totals \\
\hline $\begin{array}{l}\text { Approaches that deal with requirements without an } \\
\text { intermediate formal model }\end{array}$ & 3 \\
$\begin{array}{l}\text { Approaches that deal with requirements of an } \\
\text { intermediate formal model }\end{array}$ & 10 \\
\hline
\end{tabular}

Table 19

Notation used for formal models in requirements.

\begin{tabular}{ll}
\hline Approach & Notation \\
\hline $\begin{array}{l}\text { Software Requirements and Acceptance } \\
\text { Testing }\end{array}$ & Tree scenarios \\
Automated Test Case Generation from & State diagrams \\
Dynamic Models & \\
Testing From Use Cases Using Path Analysis & Execution flow diagrams \\
Technique & \\
SCENT & State diagrams \\
Requirement Based Testing & Cause/Effect diagrams \\
Traceability from Use Case to Test Cases & Activity diagrams \\
RETNA & State diagrams \\
A UML Based Test Generation and Execution & Activity diagrams \\
An Automatic Tool for Generating Test Cases & Sequence diagrams \\
from the System's Requirements & \\
Test Cases Generation from Use Cases & Activity diagrams \\
\hline
\end{tabular}

use different notations systems among them and only one, out of these three, uses a notation defined by UML.

The tendency to the use of UML diagrams, like activity diagrams, is increasing in the last years, due, mainly, to the use of modeldriven paradigm. The possibility of defining profiles, like the UMLTesting profile, is making the new approach use formal extensions of UML to define their solutions. For instance, the last approach shown in Table 19, defines an extension of UML included in an UMLbased tool to support the development. Besides, the use of standard models, like UML activity diagrams, assures that the approach will be more understandable for the development team because they are well-known by the software community.

\subsection{Notation for functional requirements inputs and test cases}

Another relevant aspect to consider is the disparity at the time of defining the functional requirements which are the source for the generation process. Table 20 shows the analyzed approaches and the notation used for the input requirements.

If the inputs (functional requirements) have a wide notation variety in the analyzed approaches, the outputs (functional test cases) are also defined in a wide range of formats and notations. Table 21 represents a brief summary on how each approach defines a functional system test case.

With regard to Table 21, it can be concluded that few of the approaches define a test case as a set of test steps, plus their input values and a set of constraints to validate the test case. This means that an additional work to include all lost information into the test cases is needed.

\section{Conclusions and future work}

This paper offers an overview about the situation of test cases generation from functional requirements. It starts with the procedure defined by SEG (2007) to follow a defined process when facing up this overview. This paper uses the terminology proposed by Brereton et al. (2007) in order to specify the strategy used in the development of the survey.

The research begins with the analysis of previous surveys and comparatives studies as well as the definition of the scope of the work.

After selecting the approaches of study, Table 2 represents a characterization common schema to describe each of them. The overview is presented with a briefly introduction of every approaches and their characterization schema samples. Section 5 puts forward a set of comparative analysis with relevant conclusions about the present day situation.

A set of conclusions of this survey may be summarized from the previous works analyzed in Section 2. 
Table 20

Notation for functional requirements input.

\begin{tabular}{|c|c|c|c|c|c|}
\hline \multirow[t]{2}{*}{ Approach } & \multirow[t]{2}{*}{ Tree Scenarios } & \multicolumn{3}{|l|}{ Test patterns } & \multirow[t]{2}{*}{ Text without structure } \\
\hline & & Without specific notation & With a specific notation & Implemented on the tool & \\
\hline $\begin{array}{l}\text { Software Requirements and } \\
\text { Acceptance Testing }\end{array}$ & $\mathrm{X}$ & & & & \\
\hline Testing Object-Oriented Systems & & $\mathrm{X}$ & & & \\
\hline $\begin{array}{l}\text { Automated Test Case Generation } \\
\text { from Dynamic Models }\end{array}$ & & $\mathrm{X}$ & & & \\
\hline Testing From Use Cases by Using & & $\mathrm{X}$ & & & \\
\hline Path Analysis Technique & & & & & \\
\hline $\begin{array}{l}\text { Generating Test Cases From Use } \\
\text { Cases }\end{array}$ & & $\mathrm{X}$ & & & \\
\hline Quality Web Systems & & & $\mathrm{X}$ & & \\
\hline SCENT & & & $\mathrm{X}$ & & \\
\hline Requirement Based Testing & & & & & $\mathrm{X}$ \\
\hline Traceability from Use Case to Test & & & & $\mathrm{X}$ & \\
\hline Cases & & & & & \\
\hline RETNA & & & & & $\mathrm{X}$ \\
\hline $\begin{array}{l}\text { A UML Based Test Generation and } \\
\text { Execution }\end{array}$ & & $\mathrm{X}$ & & & \\
\hline An Automatic Tool for Generating & & & & $\mathrm{X}$ & \\
\hline Test Cases from the System's & & & & & \\
\hline Requirements & & & & & \\
\hline Test Cases Generation from Use & & & $\mathrm{X}$ & $\mathrm{X}$ & \\
\hline Cases & & & & & \\
\hline
\end{tabular}

First, the conclusions from Denger and Medina's survey indicate that the authors of the approaches and processes do not follow any standards for the definition of templates (for functional requirements). On the contrary, each approach uses its own templates and format. Therefore, this conclusion is still valid, as it was mentioned in the previous section.

Another idea from Denger and Medina's report is that none of the approaches uses path analysis techniques and, as a previous step, the approaches build a more formal representation of the functional requirements. Once again, this conclusion is still appropriate.

According to Gutiérrez et al. (2006) one of the conclusions from the previous survey is that many of the existing approaches have to formalize the requirements as a first step to generate functional test cases. Again, this conclusion is still valid. In fact, this is a mandatory step in the approaches which offer a high degree of systematization and have supporting tools. However, it can be pointed out that some approaches, as it is presented in Gutiérrez et al. (2008b) offer a systematic way or even automatic ways (for instance with NDT-Suite) to generate more formal models to automate the process. In this case, this is possible because, although requirements are described in natural language, they are metamodels and some transformations from this description permit to translate requirements in natural language into activity diagrams.
As a conclusion, we can observe that three know surveys have similar results. This state of the art indicates that, there is not a definitive approach that closes the problem of generating functional text cases automatically in a satisfactory way. In fact, it implies a lack of evolution among the existing approaches. Thus, there are some aspects that may be improved, like the use of standards for the inputs and outputs, the application of the standards and more formal methods to describe the process itself, the need for empirical results, the measurement of the possible automation and a profitable tool supporting, etc.

One of the most recent ideas carried out in the last years by several authors is the use of the model-driven paradigm (MDE) in test generation (Brambilla et al., 2009; Hartman and Nagin, 2003). MDE is a new paradigm that focuses on defining a set of metamodels, which are instanced in the development process, and a set of transformations among them. Consequently, in the last year, some related works are emerging in this line. Thus, MDT (Model-Driven Testing) is providing important results in the research (Heckel and Lohmann, 2003; Kuliamin et al., 2003).

When reviewing the literature about MDT as a solution for our research question, we found a high number of papers, nevertheless only one is included with a detailed description and two others are briefly mentioned. The reason is that, despite the high number of MDT approaches, they do not match with the aim of the sur-

Table 21

Notation for test case.

\begin{tabular}{|c|c|}
\hline Approach & Test case notation \\
\hline Software Requirements and Acceptance Testing & Path in a state diagram \\
\hline Testing Object-Oriented Systems & Rows in a table (a set of values in operational variables) \\
\hline Automated Test Case Generation from Dynamic Models & Transition Sequence \\
\hline Testing From Use Cases Using Path Analysis Technique & Flow diagram paths \\
\hline Generating Test Cases From Use Cases & Text patterns \\
\hline Quality Web Systems & Text patterns \\
\hline SCENT & Path in a state diagram \\
\hline Requirement Based Testing & Natural language \\
\hline Traceability from Use Case to Test Cases (2003) & Path in a state diagram \\
\hline RETNA & Path in a state diagram \\
\hline A UML Based Test Generation and Execution & Path in a activity diagram \\
\hline An Automatic Tool for Generating Test Cases from the System's Requirements & Text patterns \\
\hline Test Cases Generation from Use Cases & Text patterns \\
\hline
\end{tabular}


vey. Thus, we only include several general references in this area because they are offering quite suitable results.

In fact, an added conclusion of the survey that guides to future works is the use of this paradigm when improving test phase. As commented in Section 5.3, this paradigm could also be useful in the coverage of other aspect that need to be improved; the definition of tools in order to support the application of each method.

Finally, we highly recommend as a basic need for future works the real application of the approaches. There are very few practical references, thus, a final feeling could be that, in the research area, we are promoting new advances in the improvement of testing but, are we sure that they are useful in the enterprise environment? If we try to apply some of the approaches presented in this paper, mainly those that do not offer any tool support, we could conclude that it is impossible when we have a high number of functional requirements, which is the most common situation in the enterprise environment.

Research groups must direct their approach to the enterprise in order to offer a suitable answer to test software.

\section{Acknowledgments}

This research has been supported by the project QSimTest (TIN2007-67843-C06_03) and by the Tempros project (TIN201020057-C03-02) of the Ministry of Education and Science, Spain.

\section{References}

Balcer, M., Hasling, W., Ostrand, T., 1990. Automatic generation of test scripts from formal test specifications. In: Proceedings of ACM SIGSOFT' 89 - Third Symposium on Software Testing, Verification, and Analysis (TAVS-3) ,. ACM Press, pp. 257-271.

Bertolino, A., Fantechi, A., Gnesi, S., Lami, G., Maccari, A., 2002. Use Case Description of Requirements for Product Lines, REPL'02, Essen, Germany, Avaya Labs Tech. Re ALR-2002-033.

Bertolino, A., Gnesi, S., 2003. Use Case-based Testing of Product Lines. ESEC/FSE’03, Helsinki, Finland.

Bertolino, A., Gnesi, S., 2004. PLUTO: A Test Methodology for Product Families. Lecture Notes in Computer Science, vol. 3014. Springer-Verlag, Heidelberg, pp. $181-197$.

Binder, R.V., 1999. Testing Object-Oriented Systems. Addison Wesley.

Boddu, R., Guo, L., Mukhopadhyay, S., 2004. RETNA: from requirements to testing in natural way. In: 12th IEEE International Requirements Engineering RE'04.

Brambilla, M., Fraternali, P., Tisi, M., 2009. A transformation framework to bridge domain specific languages to MDA. In: 4th Workshop on Model-Driven Web Engineering. LNCS, vol. 5421, France, pp. 167-181.

Brereton, P., Kitchenham, B.A., Budgen, D., Turner, M., Khalil, 2007. Lessons from applying the systematic literature review process within the software engineering domain. The Journal of System and Software 80, 271-583.

Cockburn, A., 2000. Writing Effective Use Cases, 1st ed. Addison-Wesley, USA.

Denger, C., Medina, M., 2003. Test Case Derived from Requirement Specifications. Fraunhofer IESE Report. Germany.

Dustin, E., 2002. Quality Web Systems, 1st ed. Addison-Wesley, USA.

Escalona, M.J., Aragón, G., 2008. NDT: a model-driven approach for web requirements. IEEE Transactions on Software Engineering 34 (3) 370-390.

Fikes, R.E., Nilsson, N.J., 1971. STRIPS: a new approach to the application of theorem proving to problem solving. Artificial Intelligence 2.

Fröhlich, P., Link, J., 1999. Modelling dynamic behaviour based on use cases. In: Proceedings of Quality Week Europe, Brussels.

Fröhlich, P., Link, J., 2000. Automated test case generation from dynamic models. ECOOP, 472-491, 2000.

Ryser, J., Glinz, M., 1999. A Practical Approach to Validating and Testing Software Systems Using Scenarios Quality. Week Europe QWE'99 in Brussels. Institut für Informatik, Universität Zürich.

Gutiérrez, J.J., Escalona, M.J., Mejías, M., Torres, J., 2006. Generation of test cases from functional requirements A survey. In: 4th Workshop on System Testing and Validation, Potsdam, Germany.

Gutiérrez, J.J., Escalona, M.J., Mejías, M., Torres, J., Torres-Zenteno, A.H., 2008a. A Case Study for generating test cases from use cases. In: Proceedings of RCIS, Morocco, pp. 223-228.

Gutiérrez, J.J., Nebut, C., Escalona, M.J., Mejías, M., Ramos, I., 2008b. Visualization of use cases through automatically generated activity diagrams. In: ACM/IEEE 11 th International Conference on Model-Driven Engineering Languages and Systems. LNCS, vol. 5301, pp. 83-96.
Hartman, A., Nagin, K., 2003. Model driven testing - AGEDIS architecture interfaces and tools. In: 1st European Conference on Model Driven Software Engineering , Nuremberg, Germany, December, pp. 1-11.

Heckel, R., Lohmann, M., 2003. Towards model-driven testing. Electronic Notes in Theoretical Computer Science 82 (6), 1-11.

Heumann, J., 2002. Generating test cases from use cases. Journal of Software Testing Professionals.

Huebner, M., Philippow, I., Riebisch, M., 2003. Statistical usage testing based on UML. In: Proc. of the 7th World Multi Conference on Systemics, Cybernetics and Informatics , pp. 290-295.

Hsia, P., 1994. A usage-model based approach to test the Therac-25. Safety and Reliability in Emerging Control Technologies. IFAC Workshop. Florida, USA, pp. 55-63.

Hsia, P., 1997. Software requirements and acceptance testing. Annals of software Engineering, 291-317.

IEEE 829-2008, 2008. IEEE Standard for Software and System Test Documentation.

Ibrahim, R., Saringat, M., Ibrahim, Z., Ismail, N.N., 2007. An automatic tool for generating test cases from the system's requirements. In: IEEE 7th International Conference on Computer and Information Technology CIT2007, Fukushima, Japan.

Ismail, N., Ibrahim, R., Ibrahim, N., 2007. Automatic generation of test cases from use-case diagram. In: International Conference on Electrical Engineering and Informatics. Institut Teknologi, Bandung, Indonesia, June 17-19.

Itschner, R., Pommerell, C., Rutishauser, M., 1998. GLAS.S. Remote monitoring of embedded systems in power engineering. IEEE Internet Computing 2 (3), 46-52.

Insfrán, E., Pastor, O., Wieringa, R., 2002. Requirements engineering-based conceptual modelling. Requirements Engineering Journal Vol7 (1.).

Kim, Y.G., Hong, H.S., Cho, S.M., Bae, D.H., Cha, S.D., 1999. Test cases generation from UML state diagrams. IEEE Proceedings-Software 146 (4), 187-192.

Kuliamin, V.V., Petrenko, A.K., Kossatchev, A.S., Bourdonov, I.B., 2003. UniTesK Model based testing in industrial practice. In: 1st European Conference on Model Driven Software Engineering , Nuremberg, Germany, December, pp. 55-63.

Labiche, Y., Briand, L.C., 2002. A UML-based approach to system testing. Journal of Software and Systems Modelling (SoSyM) 1 (1) $10-42$.

Legeard, B., 2010. Model-based testing: next generation functional software testing. In: Dagstuhl Seminar Proceedings 10111. Practical Software Testing: Tool Automation and Human Factors.

Liu, S., Yuting, C., 2008. A relation-based method combining functional and structural testing for test case generation. Journal of Systems and Software 81 (2), 234-248.

Mogyorodi, G., 2001. Requirements-based testing: an overview. In: 39th International Conference and Exhibition on Technology of Object-Oriented Languages and Systems (TOOLS39), p. 0286.

Mogyorodi, G., 2002. Requirements-based testing: ambiguity reviews. Journal of Software Testing Professionals, 21-24.

Mogyorodi, G., 2003. What is requirements-based testing? In: 15th Annual Software Technology Conference, Salt Lake City, USA, April 28-May 1.

Naresh, A., 2002. Testing from use cases using path analysis technique. In: International Conference On Software Testing Analysis \& Review.

Nebut, C., Fleurey, 2003. Requirements by contract allow automated system testing. In: Proceedings of the 14th International Symposium of Software Reliability Engineering (ISSRE'03), Denver, Colorado, EEUU.

Nebut, C., Fleury, F., Le Traon, Y., Jézéquel, J.M., 2006. Automatic test generation: a use case driven approach. IEEE Transactions on Software Engineering 32 (3).

NDT-Suite, 2008. Available from: www.iwt2.org/ndt (Last visit 2/2011).

Oh, J., Lee, H., Park, H., Kim, J., Choi, K., Jung, K., 2008. A single requirement modelling with graphical language for embedded system. The KIPS Transactions: Part D 15-D (4), 505-512, 2008.

Ostrand, T.J., Balcer, M.J., 1988. Category-partition method. Communications of the ACM, 676-686.

Pérez, B., Polo, M., Piatini, M., 2009. Software product line testing - a systematic review. In: 4th International Conference on Software and Data Technologies (ICSoft 2009).

Riebisch, M., Philippow, I., Götze, Marco, 2002. UML-based Statistical Test Case Generation. Net Object Days, Erfurt, Germany, October 7-10.

Robles, E., Grigera, J., Rossi, G., 2009. Bridging Test and model-driven approaches in web engineering. In: 9th International Conference on Web Engineering. LNCS, vol. 5648 , pp. $130-150$.

Ruder, A., 2004. UML-based test generation and execution. In: Rückblick Meeting , Berlin.

Rutherford, M.J., Wolf, A.L., 2003. A case for test-code generation in modeldriven systems. In: Proceedings of the Second International Conference on Generative Programming and Component Engineering , pp. 377-396.

Ryser, J., Glinz, M., 2003. Scent: A Method Employing Scenarios to Systematically Derive Test Cases for System Test. Technical Report 2000/03, Institut für Informatik, Universität Zürich.

SEG (Software Engineering Group), 2007. Guidelines for Performing Systematic Literature Reviews in Software Engineering Version 2.3. EBSE Technical Report EBSE-2007-01. School of Computer Science and Mathematics, Keel University and Department of Computer Science, University of Durham, United Kingdom.

Stocks, P., Carrington, D., 1996. A framework for specification-based testing. IEEE Transaction on Software Engineering 22 (11). 
TerMaat, P., 2001. Adventures in automated testing! The Software Testing and Quality Engineering Magazine, May/June.

Vegas, S., Juristo, N., Brasili, V.R., 2009. Maturing software engineering knowledge through classifications: a case study on unit testing techniques. IEEE Transactions on Software Engineering 35 (4), 551-565.

Wood, D., Reis, J., 2002. Use Cased Derived Test Cases. StickyMind. www.stickymind.com.

Zielczynski, P., 2006. Traceability from use cases to test cases. Available from: www.ibm.com/developerworks/rational/library/04/r-3217 (Last visit 02/2011). 